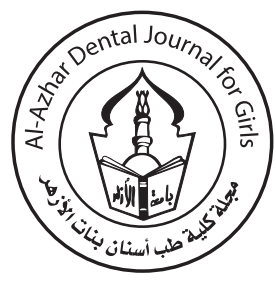

\title{
Assessment of Accelerating Orthodontic Tooth Movement by Hard Laser Corticotomy
}

\author{
Basma B. Hasaneen ${ }^{1 *}$, Samir A. Ibrahim² ${ }^{2}$, Naglaa S. El-Kilani ${ }^{3}$, Maha M. Mohamed ${ }^{4}$
}

\begin{tabular}{l} 
Codex : 17/22.01 \\
azhardentj@azhar.edu.eg \\
http://adjg.journals.ekb.eg \\
\hline DOI: 10.21608/adjg.2021.28816.1258 \\
\hline $\begin{array}{l}\text { Pediatric Dentistry \& Orthodontics } \\
\text { (Pediatric Dentistry, Orthodontics) }\end{array}$
\end{tabular}

\section{KEYWORDS}

Retraction, Corticotomy,

Laser, Cone Beam Computed

Tomography.

\begin{abstract}
Purpose: The study was done for comparing the rate of canine retraction in addition to anchorage loss (mesial movement of the first permanent molar) with hard laser corticotomy versus conventional method of tooth movement. Patients and methods: Eighteen patients with an age range from 15 to 18 years, requiring orthodontic treatment with bimaxillary dento-alveolar protrusion were selected. The extraction of the upper first bicuspids was required followed by cuspid distalization.Patients were randomly divided into two equal groups, group I the two sides of the maxillary arch were treated by conventional canine retraction, while group II, corticotomy by hard tissue laser was used before starting the canine retraction. The coil springs were placed between the canine and the miniscrews positioned between second bicuspid and first permanent molar. Canine retraction was measured four times every 2 months from starting the retraction till 6 months of retraction. Results: The canine retraction rates was faster in hard laser corticotomy group than that in a conventional group. Forward movement of the first permanent molars were registered in both groups. In the laser group pain significantly decreased by time. In the laser group the mean value of oedema increased by time. Conclusion: Hard laser corticotomy technique is an efficient procedure that reduce the time needed for canine distalization and educe the post-surgical pain.
\end{abstract}

\section{INTRODUCTION}

A process of orthodontic tooth movement combines adaptation of the alveolar bone to mechanical strains with minute trauma to the

* Paper extracted from Doctor Thesis titled; (Assessment of Accelerating Orthodontic Tooth Movement by Hard Laser Corticotomy)

1. Assistant lecturer of Orthodontic Department, Faculty of Dental Medicine for Girls, Al-Azhar University, Cairo, Egypt.

2. Professor of Orthodontic Department, Faculty of Dental Medicine for Girls, Al-Azhar University, Cairo, Egypt.

3. Professor and head of Department of Oral medicine, Periodontology, Diagnosis and Radiology, Faculty of Dental Medicine for Girls, Al-Azhar University, Cairo, Egypt.

4. Lecturer of Orthodontic Department, Faculty of Dental Medicine for Girls, Al-Azhar University, Cairo, Egypt

* Corresponding author email: drbasmabadr60@gmail.com 
periodontium. In healthy situations, such movement is achieved by bone remodeling, which combines bone deposition following bone resorption ${ }^{(1)}$.

The number of patients are demanding orthodontic treatment for improving their life by enhancing dental and jaw functions as well as dentofacial esthetics have been increased. One of the important challenges of orthodontic treatment faced by both patients and orthodontists is the treatment duration. The rate of biological orthodontic tooth movement is approximately $1 \mathrm{~mm}$ over 4 weeks. Accordingly, in cases of upper premolar extraction and maximum anchorage, distalization of canines can take almost 7 months, leading to a total treatment duration of 2 years ${ }^{(2)}$.

The monthly rate of orthodontic tooth movement in traditional treatment was assessed in a large number of studies showing about $1 \mathrm{~mm}$ of distance the tooth can be moved ${ }^{(3,4)}$. Acceleration of orthodontic tooth movement is done by biological methods, physical methods, and surgical methods ${ }^{(5)}$.

The biological method is done by local injection of biomodulators that enhance the activation or recruitment of the osteoclasts such as PGE2 (6), parathyroid hormone, thyroxine hormone. But all of these biomodulators need daily administration and frequent injections ${ }^{(7)}$.

The 1960s was the decade for laser introduction, a large number of materials was used as a media with unique wavelengths have been tested for coagulation, vaporization, and cutting of different hard and soft tissues ${ }^{(8-12)}$.

Corticotomy has become a surgical method for rapid orthodontic tooth movement, in which the cortical layer was removed till reaching to the level of the spongiosa. A regional acceleratory phenomenon (RAP) happens around the tooth during the healing period. RAP is an immune response of the periodontal tissues upon its exposure to an injury, and is associated with increased perfusion, bone turnover and decreased bone density ${ }^{(13,14)}$. The frac- ture healing process and RAP phenomenon are very similar in their phases which include a reactive period, a reparative period, and remodeling period. The reactive period take a week and it is characterized by sudden narrowing of blood channels to stop the bleeding, and then heamatoma formation ${ }^{(13)}$.

The ideal method for reducing the surgical trauma and bone damage in corticotomy is by using a piezoelectric device instead of using the surgical bur $^{(15)}$. The rate of orthodontic tooth movement with corticotomies is double than that without. But acceleration of orthodontic tooth movement is limited to two months after surgery ${ }^{(15)}$.

Laser-based technology was a dream for oral surgery to find a new tool for the bone cutting. Using of pulsed erbium-doped yttrium aluminium garnet (Er:YAG) lasers showed effective cutting tool with minimum degree of carbonization ${ }^{(16)}$.

So, the present study was carried out to assess the rate of canine retraction by using the hard laser corticotomy as an accelerating method of orthodontic tooth movement.

\section{PATIENTS AND METHODS}

\section{Sample size calculation:}

Calculation were made using Epicalc program (version 1.02) to determine the power and sample size for this study. For a statistical power of $80 \%$ it has been calculated that 18 patients were included in this study. The patients aged 15-18years old with the following criteria: dentoalveolar bimaxillary protrusion, no previous orthodontic treatment, no presence of root resorption on the pretreatment panoramic radiographs, good oral hygiene, high motivation and cooperation.

The study was certified by the Research Ethics committee, Faculty of Dental Medicine for Girls, Al-Azhar University (REC code (NO. ORTHO108-6G) and a signed informed consent form with approval was obtained from each participant. 
Patients were equally divided into two groups: Group I: A control group in which a conventional method of canine retraction was performed on the right and left sides of the upper jaw; and Group II: A study group in which hard laser corticotomy before the canine retraction was performed on the right and left sides of the upper jaw.

The foremost phase of teeth alignment and leveling was completed first with a straight wire 0.022 -in slot Roth appliance. (Fig. 1)

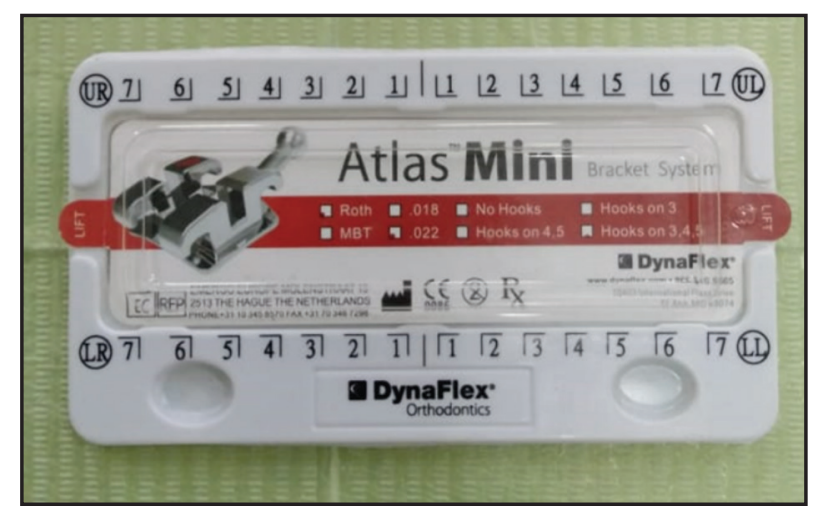

Figure (1) Straight wire 0.022-in slot Roth appliance

\section{Surgical protocol}

Corticotomy was done in Al Azhar Dental Laser Center, at the Faculty of Dental Medicine for Girls, using Waterlase MD ${ }^{\mathrm{TM}}$ Turbo all-tissue laser (Biolase Technology, Inc.USA). Laser cut protocol parameter as follows: Water level control: $50 \%$, Air level control: $70 \%$, Power level control: $4 \mathrm{~W}$ Pulse mode control: $\mathrm{H}$

\section{Steps for the Biolase corticotomy}

Distal incision was made through the gingiva on the buccal surface of the canine with a surgical blade. Hard laser corticotomy cuts involved performing incisions in gingiva and vertical cuts in cortical bone without flap reflection. Vertical interproximal cuts were done $5 \mathrm{~mm}$ Apical to interdental papillae distal to upper canine. Cuts lengths were about $10 \mathrm{~mm}$ in apical direction. (Fig. 2)

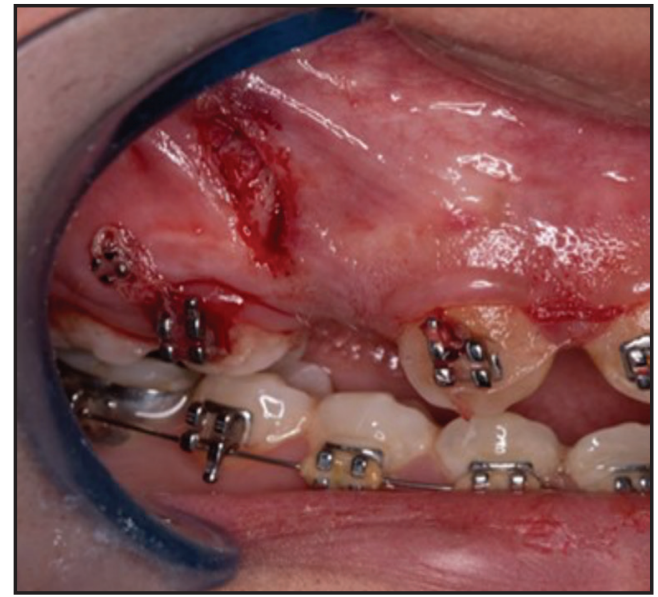

Figure (2) Showing the laser cut

In both groups, a heavy stainless steel wire was placed and canine retraction started with nickeltitanium closed-coil springs that applied $180 \mathrm{~g}$ of force on each side. Cuspid distalization started immediately after surgery to allow RAP phenomenon to start by the periodontal ligament. The miniscrew placed between second bicuspid and first permanent molar that represent the anchor point on which the coil spring stretched to allow the canine retraction.

For canine retraction, the initial leveling and alignment was followed by placement of an upper continuous $0.016^{\prime \prime} \times 0.022 "$ stainless steel arch wire. The arch was left in situ for 3 weeks before initiation of canine retraction. This period enabled full arch wire passivity before retraction of the maxillary canines.

The distal retraction of the maxillary right and left canines was performed using a prefabricated $9 \mathrm{~mm}$ super elastic Nickel-Titanium closed coil spring. The distal wing of the canine bracket was fixed using 0.009 -inch wire ligature wire to the arch wire to avoid rotation of the canine during retraction.

\section{Measurements:}

\section{A) Models preparation:}

The rate of canine distal displacement was measured from four models, for calculating the distal 
movement of cuspids every 60 days. Four alginate impressions were taken for the maxillary arch for each patient using the same impression material every time. The impression was immediately poured in plaster to make the model.

The impression were taken at the following intervals:

1. The first impression at day 0 (T0) before the first mechanical activation of the NiTi coil spring, considered as a baseline.

2. The second impression after 2 months (T1), to calculate the canine retraction rate in first interval.

3. The third impression after 4 months (T2), to calculate the canine retraction rate in the second interval.

4. Fourth impression after 6 months (T3) to calculate the canine retraction rate in third interval

\section{B) 3D Cast Scan:}

A 3D laser scanning was done for every cast to get a 3D digital replica for every cast. The scanned images were saved as Streolithography (STL) file format. For every patient, 4 study model were scanned. ( Fig. 3)

\section{C) Software analysis:}

The 3D Scanned STL files were imported into the software. For every patient, the 4 study models were superimposed over each other by the free hand

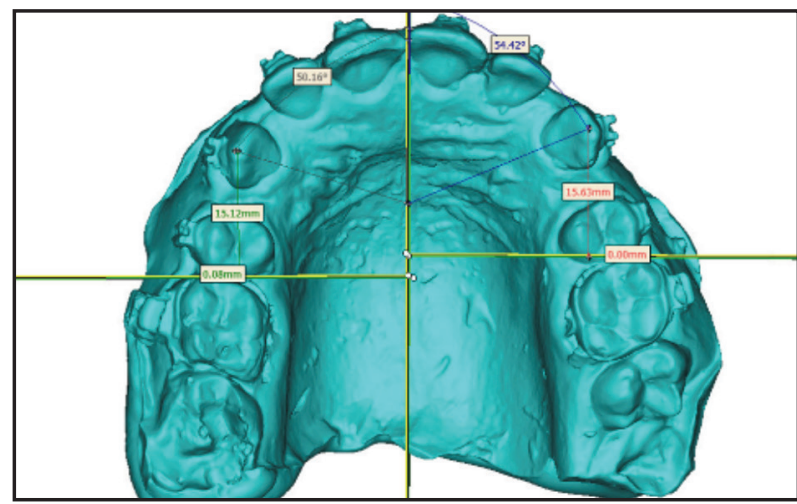

Figure (3) Showing the 3D Cast Scan

superimposition technique; then measurements were done for every cast using the 3D linear ruler tool in the software in $\mathrm{mm}$.

The distance moved by the maxillary canine was measured from its cusp tip to its side horizontal plane as a perpendicular 3D line; while the amount of mesial movement of the $1^{\text {st }}$ maxillary molar was measured from the most mesial point on the mesial marginal ridge to the reference horizontal plane in order to measure the anchorage loss.

\section{RESULTS}

\section{Regarding the rate of canine retraction:}

Descriptive data of the distance moved by maxillary canine (mean, confidence intervals, standard deviation, minimum, maximum range, and median), in the different time periods (T0- T1, T1-T2, T2-T3 and overall). (Fig. 4)

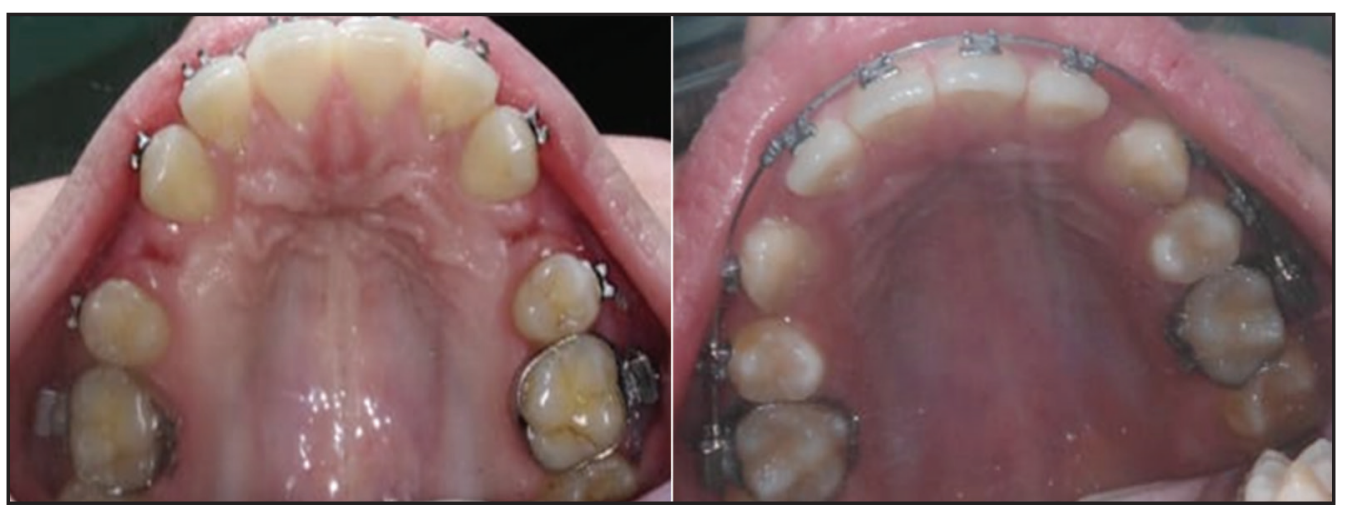

Figure (4) Showing canine retraction (a) before canine retraction, (b) after canine retraction 
Comparison of the 2 groups are presented in (Table 1)

Overall, a higher median value (6.44), was recorded in laser group, in comparison to (4.91) the conventional group.

\section{Regarding the anchorage loss}

Descriptive data of anchorage loss (mean, standard deviation, and median), in the different time intervals (T0-T1, T1-T2, T2-T3) and overall and comparison of the 2 groups are presented in (Table 2)

Overall, both groups recorded the same median value (0.72). Mann Whitney test revealed that the difference between both groups was not statistically significant $(\mathrm{p}=0.486)$.

\section{Regarding post-surgical pain for laser group:}

The mean value of pain post-surgical in laser group had significantly decreased by time $(\mathrm{p}=0.03)$,

Table (1): Comparison of tooth movement rate in control and test groups.

\begin{tabular}{c|c|c|c|c|c}
\hline \multicolumn{2}{c|}{ Groups } & T0-T1 & T1-T2 & T2-T3 & Overall \\
\hline \multirow{3}{*}{ Group I (Conventional) } & Mean & -3.22 & -1.68 & -.41 & -5.31 \\
\cline { 2 - 6 } & Median & -2.79 & -1.43 & -.77 & -4.91 \\
\cline { 2 - 6 } & Std. Deviation & 1.92 & .68 & .92 & 1.38 \\
\hline \multirow{3}{*}{ Group II (Laser) } & Mean & -3.02 & -1.59 & -1.76 & -6.37 \\
\cline { 2 - 6 } & Median & -3.17 & -1.64 & -1.65 & -6.44 \\
\cline { 2 - 6 } & Std. Deviation & 1.24 & 1.22 & .66 & .88 \\
\hline
\end{tabular}

Significance level $p \leq 0.05$, *significant, $n s=$ non-significant

Table (2) Descriptive data of anchorage loss in both groups and comparison between groups (Mann Whitney U test)

\begin{tabular}{ccccccc}
\hline & Groups & & T0-T1 & T1-T2 & T2-T3 & Overall \\
\hline \multirow{2}{*}{ Group I (Conventional) } & Mean & .22 & .15 & .14 & .51 \\
\cline { 2 - 6 } Group II (Laser) & Median & .00 & .22 & .20 & .72 \\
\cline { 2 - 6 } & Std. Deviation & .33 & .47 & .61 & .38 \\
\cline { 2 - 6 } & Mean & .17 & .07 & .48 & .74 \\
\hline P value (comparison between groups) & Std. Deviation & .12 & .05 & .27 & .24 \\
\hline
\end{tabular}

Significance level $p \leq 0.05$, ns=non-significant 


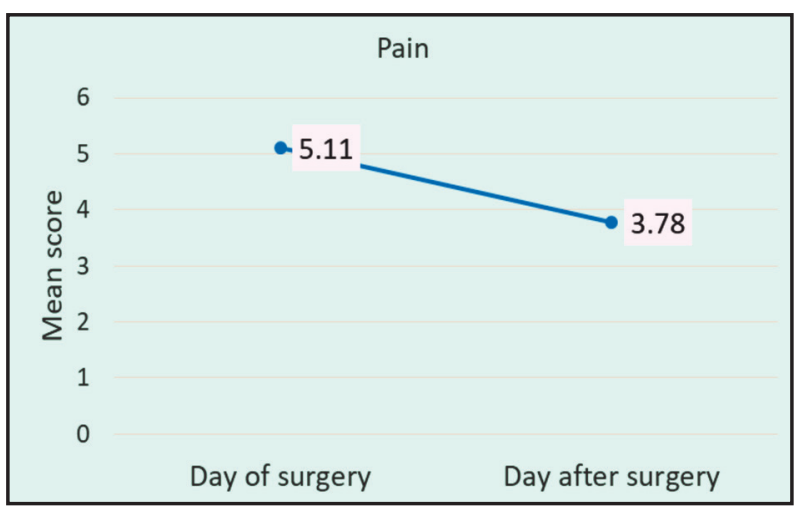

Figure (5) Line chart showing mean pain score post-surgical in laser group

\section{DISCUSSION}

\section{Regarding the rate of canine retraction:}

Several methods were used to reduce the orthodontic treatment duration by increasing the rate of orthodontic tooth movement. These methods can be divided into different approaches such as biological materials, physical methods and surgical techniques ${ }^{(17)}$.

Increasing the rate of orthodontic tooth movement is preferred and one of the adult orthodontic patient's needs. Those create a motive for every orthodontist to looking for different modalities that may help in decreasing the treatment time.

The present study showed that there was a statistically significant difference between laser and conventional retraction groups in the rate of canine retraction, where the laser group showed increase in the rate of orthodontic movement compared to the conventional group of retraction.

This increase in the rate of orthodontic tooth movement with corticotomy by using the hard laser detected in the present study were in agreement with a previous study that concluded that piezocisionassisted canine distalization increases the rate of canine distalization ${ }^{(17)}$. It is also, in accordance with another study that compared the effect of corticotomy-facilitated orthodontics and Piezocision on the rate of canine retraction and concluded that corticotomy and Piezocision are considered as effective treatment tools for accelerating canine distalization $^{(18)}$.

These results agree with the mechanism of RAP phenomenon, which is characterized by transient bone demineralization and increased bone metabolism. The regional acceleratory phenomenon (RAP) is a localized reaction of tissues to any harmful stimuli, regeneration occurs faster than normal (i.e., without stimuli) in a regional regeneration/remodeling process. This reaction of tissues changes according to size, intensity, and duration of the stimulus, and it is considered a physiological reaction for the healing of injuries that may help in tissue survival ${ }^{(19)}$.

\section{Regarding anchorage loss}

Anchorage loss was also calculated in all groups. Although the canine retraction was miniscrews supported but the mesial movement of the first permanent molar was assumed due to dental mesial drifting tendency ${ }^{(20)}$.

\section{Regarding the pain assessment}

The pain perception was measured in the laser group only after surgery by Visual analogue scale due to its superiority on other scales. The mean value of pain post-surgical in laser group had significantly decreased by time. This could be attributed to the mechanism of laser cell interaction by stimulation of photoreceptors in the mitochondria respiratory chain, change in cellular ATP levels and cell membrane stabilization in addition to increasing the level of Receptor activator of nuclear factor$x \mathrm{~B}$ ligand (RANKL) during orthodontic tooth movement, which subsequently reduced pain in a very short period of time ${ }^{(21,22)}$.

\section{CONCLUSIONS}

Within the limitations and findings of the present study, it could be concluded that hard laser corticotomy technique is an efficient procedure that reduce the time needed for canine distalization and reduce the post-surgical pain. 


\section{CONFLICT OF INTEREST}

None declared.

\section{FUNDING}

No funding was received for this study.

\section{REFERENCES}

1. Chen SS, Hartsfield JK, Roberts WE. Biological aspects of bone growth and metabolism in orthodontics. In Biological mechanisms of tooth movement. Wiley Blackwell. 2015; 26:62-81.

2. Aksakallia S, Berra Calik B, Burcak Kara B, Ezirganli S. Accelerated tooth movement with piezocision and its periodontal transversal effects in patients with Class II malocclusion. Angle Orthod. 2016; 86:59-64.

3. Kumar MB, Birhman AS, Kannan SH, Shaker CL. Measurement of initial displacement of canine and molar in human maxilla under different canine retraction methods using digital holographic interferometry. Optical Eng. 2018; 57:94-106.

4. Monini AD, Gandini LG, Vianna AP, Martins RP. Tooth movement rate and anchorage lost during canine retraction: A maxillary and mandibular comparison. Angle Orthod 2019; 89:559-65.

5. Andrade I, Jr, Sousa AB, Silva GG. New therapeutic modalities to modulate orthodontic tooth movement. Dental Press J Othod.2014; 19:123-33.

6. 6- Kouskoura TP, Katsaros CK, Von Gunten SR. The potential use of pharmacological agents to modulate orthodontic tooth movement. Front Physiol. 2017; 8:67-77.

7. Li Y, Chen XY, Tang ZL, Tan JQ, Wang DX, Dong Q. Differences in accelerated tooth movement promoted by recombinant human parathyroid hormone after mandibular ramus osteotomy. Am J Orthod Dentofacial Orthop. 2019; 155: $670-80$.

8. Abd El-Ghafour M, El- Ashmawi NM, El-Beialy AR, Fayed MS, Eid F. Effect of low level laser therapy on the rate of canine retraction in orthodontic patients: a splitmouth randomized controlled trial. Orthod practice US. 2017; 8:18-24.

9. Attia MS, Hazzaa HH, Al-Aziz FA, Elwan GM. Evaluation of adjunctive use of low- level diode laser biostimulation with combined orthodontic regenerative therapy. J Int Acad Periodontol. 2019; 21:63-73.
10. Sedky Y, Refaat W, Gutknecht N, Al Kady A. Comparison between the effect of low-level laser therapy and corticotomy- facilitated orthodontic RANKL release during orthodontic tooth movement: a randomized controlled trial. Laser in Dental Science 2019; 3: 99-109.

11. Skondra FG, Koletsi D, Eliades T, Farmakis ET. The effect of low- level laser therapy on bone healing after rapid maxillary expansion: a systematic review. Photomed laser surg. 2018; 36:61-71.

12. El-Hosieny RA, Ibrahim SA, Abd El-Samad FA, Hafez HS. Evaluation of low intensity laser on the rate of orthodontic tooth movement. ADJG 2017; 4:71-8.

13. 13. Alfawal AM, Hajeer MY, Ajaj MA, Hamadah O, Brad B. Effectiveness of minimally invasive surgical procedures in the acceleration of tooth movement: a systematic review and meta-analysis. Prog Orthod. 2016; 17:33.

14. Kotrikova B, Wirtz R, Krempien R, Blank J. Piezosurgery: a new safe technique in cranial osteoplasty. Int $\mathrm{J}$ Oral Maxillofac Surg. 2006; 35:461-5.

15. Buschang PH, Campbell PM, Ruso S. Accelerating tooth movement with corticotomies: Is It Possible and Desirable Seminars in Orthodontics. 2012;18:286-94.

16. Colvard MD, Pick RM. Future directions of lasers in dental medicine. Curr Opin Periodontol. 1993:144-50.

17. Fisher M, Wenger R, Hans M. Pretreatment characteristic associated with orthodontic treatment duration. Am J Orthod Dentofacial Orthop. 2010; 137:178-86.

18. 18- Abbas N, Sabet N , Hassan I. Evaluation of corticotomy-facilitated orthodontics and piezocision in rapid canine retraction. Am J Orthod Dentofacial Orthop.2016; 149:473-80.

19. Shoreibah E, Ibrahim S, Attia M, Diab M. Clinical and radiographic evaluation of bone grafting in corticotomyfacilitated orthodontics in adults. J Int Acad Periodontol. 2012; 14:105-13.

20. Moumneh M, Saleh F, Attia N. A clinical assessment of miniscrews as anchorage sources in terms of stability, rate of tooth movement, and anchorage loss. Eur Sci J. 2014; 10:1857-62.

21. Deshpande P, Patil K, Mahima VG, Shivalinga BM, Suchetha M, Ranjan. Low-level laser therapy for alleviation of pain from fixed orthodontic appliance therapy: a randomized controlled trial. J Adv Clin Res Insights. 2016; 3:43-6.

22. Youssef M,Ashkar S, Hamade E, Gutknecht N, Lampert F, Mir M. The effect of low-level laser therapy during orthodontic movement: A preliminary study. Lasers Med Sci $2008 ; 23: 27-33$. 